\title{
An approximate approach to estimation of dissociation rate of gas hydrate in porous rock bed
}

\author{
Andrii Dreus ${ }^{1 *}$, Oleksandr Gubin ${ }^{1}$, Volodymyr Bondarenko ${ }^{2}$, Roman Lysenko ${ }^{2}$, and \\ Baochang Liu ${ }^{3}$ \\ ${ }^{1}$ Oles Honchar Dnipro National University, Department of Fluid Mechanics and Energy \& Mass \\ Transfer, 72 Haharina Ave., 49089, Dnipro, Ukraine \\ ${ }^{2}$ Dnipro University of Technology, Department of Mining Engineering and Education, \\ 19 Yavornytskoho Ave., 49005, Dnipro, Ukraine \\ ${ }^{3}$ Jilin University, College of Construction Engineering, 938 Ximinzhu St, 130061, Changchun, China
}

\begin{abstract}
Development of deep shelf or onshore gas hydrate fields involves drilling wells with subsequent thermal, decompression or chemical action on the bed. In this case, the radius of thermal or decompression action is limited. As the field develops, recovery efficiency decreases, and necessity arises for drilling a new well that influences the cost of the technology. To determine the rational wells location, it is necessary to predict the advance of the phase transformation rate front into the depth of the bed. In this work, to study the movement dynamics of the gas hydrates dissociation front in a porous layer of rock, the Stefan problem solution is used. The method adequacy is substantiated by comparing the calculated results with known experimental data. The temperature fields are modelled in a porous bed during the methane hydrate dissociation. The temperature field dynamics for 200 days in a porous bed during the methane hydrate dissociation caused by thermal action is shown. The influence of porosity and excess temperature on the dissociation front movement rate is revealed.
\end{abstract}

\section{Introduction}

The natural gas hydrate deposits are considered as one of the potential energy reserves of humanity [1-3]. Most natural gas hydrates are formed under the influence of specific thermodynamic conditions (high pressures and low temperatures) and occur in rocks at great depths, in permafrost conditions, on the shelf of seas and oceans. Gas hydrate reserves can be found in Europe, including Ukraine [4], both on the shelf of the Black Sea [5], and in coal beds of deep mines $[6,7]$. Mine rocks, which are a porous medium, are a reservoir in the pore space of which gas hydrates are formed and stored. Disturbance of the thermodynamic equilibrium conditions at the boundary of the porous reservoir leads to the beginning of the phase transition "gas hydrate - gas" process, as well to the filtration of the released gas volume to the boundary. The dynamics of the gas hydrate dissociation process

*Corresponding author: dreus@mmf.dnu.edu.ua 
in pores determines the change in the area of gas hydrate decomposition with time. This problem is of great practical importance, since it allows to predict the size of gas hydrate decomposition zones around producing wells.

A fairly large number of works are devoted to the study of the gas hydrates dissociation processes in porous media [8]. The papers [9-11] provide an overview of technologies for the gas hydrates recovery from porous media and the modelling specifics of such processes in natural fields. It should be noted that experimental research in real mines and wells is associated with a number of unbiased difficulties [11, 12]. An effective tool for studying the gas hydrates dissociation processes in porous mine rocks is mathematical modelling. Basics of mathematical modelling of gas hydrate phase transitions in porous media are studied in the work [13]. Using this approach, a large number of problems have been solved for modelling the heat transfer processes in porous media during the gas hydrates decomposition, as shown in the works $[14,15]$. In some simple cases, such problems admit an analytical solution in a self-similar form [17]. However, in most cases, such problems are solved within the framework of the Stefan model using the appropriate numerical methods [17]. The statistical processing of experiments and stochastic approaches are also used [18]. Such solutions are less versatile and are not always convenient for practical use in express assessments and research into the influence of various factors on the dissociation process. In this paper, a simplified approach is proposed to an assessment of the front movement rate of a gas hydrate phase transition in a porous layer based on the analytical solution of the Stefan problem.

\section{Mathematical model}

In the general case, modelling the transfer processes during the "gas hydrate - gas + water" phase transition is a rather complex problem that needs to be solved taking into account the transfer processes in the well [19] and changes in thermodynamic conditions along the well depth [20]. However, in the case when the gas hydrate layer thickness is much less than the depth of the well, the radius of the gas hydrate decomposition area is much larger than the radius of the well, and the upper and lower layers of the mine rock are impermeable to gas, then the problem can be solved within the framework of the one-dimensional approximation [21, 22].

Let us consider the problem of the methane gas hydrate $\mathrm{CH}_{4}$ decomposition in a porous rock layer in accordance with the scheme in Fig. 1.

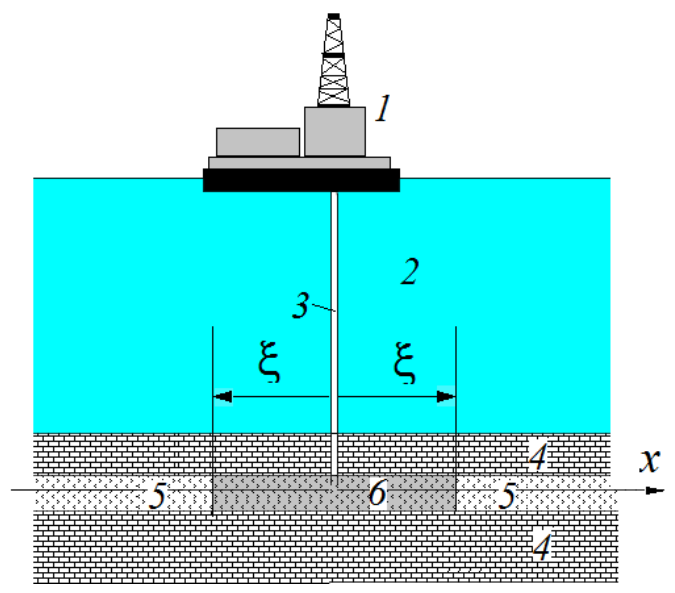

Fig. 1. Scheme to model: 1 -drilling outfit; 2 -sea; 3 -well; 4 -impermeable rock; 5 -zone of stability hydrate; 6 - zone of dissociated hydrate; and $\xi$-dissociation radius. 
Assume that the hydrate-containing layer is located at a sufficiently large depth, which allows gas hydrate to exist at relatively high (positive) temperatures. The gas hydrate dissociation process occurs due to an increase in temperature at the boundary of the bed, namely, in the well. Transfer processes take place along the hydrate-containing layer. Consider the problem in a plane coordinate system, the origin of which is located on the wall of the well. The phase transformation occurs instantly on the phase transition line $\xi$ with the corresponding thermodynamic parameters. Thus, two zones are formed: a zone of existence of a stable gas hydrate and a zone of dissociated hydrate.

In the general case, to describe the transfer processes in a porous bed during the gas hydrates dissociation, it is necessary to use a complex system of interrelated equations of energy and filtration for each of the zones. However, in the first approximation, if the pressure changes along the bed are low compared to the absolute values, the thermal problem can be considered separately from the filtration one [23]. We will also neglect the change in moisture content in temperature fields. For the case when the phase transition front moves on a sufficiently large distance into the depth of the bed, we can write:

$$
\begin{array}{cl}
(c \rho)_{1} \frac{\partial T_{1}}{\partial \tau}=\frac{\partial}{\partial x}\left(\lambda_{1} \frac{\partial T_{1}}{\partial x}\right), & 0 \leq x \leq \xi(\tau) ; \\
(c \rho)_{2} \frac{\partial T_{2}}{\partial \tau}=\frac{\partial}{\partial x}\left(\lambda_{2} \frac{\partial T_{2}}{\partial x}\right), & \xi(\tau) \leq x<\infty,
\end{array}
$$

where $c$ - heat capacity; $\rho$ - density; $\lambda$ - thermal conduction; $\tau$ - time; $T$ - temperature; $x$ coordinate along the porous bed; $\xi$ - position of the phase transition front, indices " 1 " and " 2 " refer to the zones of dissociated and stable hydrate, respectively.

In terms of the one-temperature model, the thermophysical properties of the porous medium are determined from the ratios:

$$
\begin{gathered}
\lambda_{1}=m\left(1-S_{w}\right) \lambda_{g}+m S_{w} \lambda_{w}+(1-m) \lambda_{s} \\
(c \rho)_{1}=m S_{w} \rho_{w} c_{w}+m\left(1-S_{w}\right) \rho_{g} c_{g}+(1-m) \rho_{s} c_{s} \\
\lambda_{2}=m\left(1-S_{h}\right) \lambda_{g}+m S_{h} \lambda_{h}+(1-m) \lambda_{s} \\
(c \rho)_{2}=m\left(1-S_{h}\right) \rho_{g} c_{g}+m S_{h} \rho_{h} c_{h}+(1-m) \rho_{s} c_{s}
\end{gathered}
$$

where $m$ - porosity; $S$ - saturation of pores with each phase, indices " $w$ ", " $g$ ", " $h$ ", "s" refer to water, gas, hydrate and rock skeleton, respectively.

It is obvious that the balance conditions are satisfied:

$$
\left.\begin{array}{ll}
S_{g}+S_{w}=1, & 0 \leq x<\xi(\tau) \\
S_{g}+S_{h}=1, & \xi(\tau) \leq x<\infty
\end{array}\right\} .
$$

In the first zone, the value $S_{w}$, in general, will not be constant due to the dissociation of the hydrate into gas and water. However, in terms of the adopted model, we will neglect such a change. The boundary conditions for (1) and (2) have the form:

$$
\begin{array}{cc}
x=0: & T_{1}=T_{w} ; \\
x \rightarrow \infty: & T_{2}=T_{r} ;
\end{array}
$$




$$
\begin{gathered}
x=\xi(\tau): \quad T_{1}=T_{2}=T_{f} ; \\
x=\xi(\tau): \quad \lambda_{1} \frac{\partial T_{1}}{\partial x}-\lambda_{2} \frac{\partial T_{2}}{\partial x}=m \rho_{h} L \frac{d \xi}{d \tau},
\end{gathered}
$$

where $T_{w}$ - temperature in the well; $T_{r}$ - mine rock temperature; $T_{f}$ - phase transition temperature; $L$ - latent heat of phase transition.

The phase transition temperature of methane gas hydrate at a given pressure can be determined by the Antoine formula [24]:

$$
T_{f}=\frac{9459}{49.3185-\ln P_{f}},
$$

Where $P_{f}$ - bed pressure at the depth considered. It is known [25], that the movement rate of the phase transition line is proportional to $\sqrt{\tau}$ :

$$
\xi=K \sqrt{\tau},
$$

where $K$ - a constant. It is assumed that at the initial moment of time the temperature in the dissociated hydrate zone 1 is equal to the temperature $T_{w}$, and in the stable gas hydrate zone is $T_{r}$. System (1)-(7) is a formulation of the Stefan problem, the analytical solution of which has the form [24]:

$$
\begin{aligned}
& \frac{T_{1}-T_{w}}{T_{f}-T_{w}}=1-\frac{\operatorname{erf}\left(\mathrm{x} / 2 \sqrt{a_{1} \tau}\right)}{\operatorname{erf}\left(K / 2 \sqrt{a_{1}}\right)}, \\
& \frac{T_{2}-T_{f}}{T_{r}-T_{f}}=1-\frac{1-\operatorname{erf}\left(\mathrm{x} / 2 \sqrt{a_{2} \tau}\right)}{1-\operatorname{erf}\left(K / 2 \sqrt{a_{2}}\right)},
\end{aligned}
$$

where $a_{i}=\frac{\lambda_{i}}{(c \rho)_{i}}-$ temperature conductivity coefficient, $i=1$, 2. The constant $K$ is determined from the transcendental equation:

$$
\frac{\left(T_{w}-T_{f}\right) \lambda_{1} \exp \left(-K^{2} / 4 a_{1}\right)}{\sqrt{\pi a_{1}} \operatorname{erf}\left(K / 2 \sqrt{a_{1}}\right)}-\frac{\left(T_{f}-T_{r}\right) \lambda_{2} \exp \left(-K^{2} / 4 \sqrt{a_{2}}\right)}{\sqrt{\pi a_{2}}\left(1-\operatorname{erf}\left(K / 2 \sqrt{a_{2}}\right)\right)}=m S_{h} \rho_{h} L \frac{K}{2} .
$$

Thus, under the accepted assumptions, equations (7)-(10) make it possible to study thermophysical processes in a porous layer of mine rock during the gas hydrates dissociation.

\section{Results and discussion}

To assess the efficiency of the considered approach, a comparative analysis of the calculation results has been conducted with the data of the work [27], which presents the results of mathematical processing of experimental data on the methane gas hydrate dissociation in sand. According to the initial data [27] $S_{h}=0.1, m=0.44, \rho_{s}=2560 \mathrm{~kg} / \mathrm{m}^{3}$, $c_{s}=800 \mathrm{~J} /(\mathrm{kg} \cdot \mathrm{K})$, the value of the thermal conduction coefficient $\lambda_{s}$ varied depending on the moisture content of the sand $0.5 \mathrm{~W} /(\mathrm{m} \cdot \mathrm{K}), 1.5 \mathrm{~W} /(\mathrm{m} \cdot \mathrm{K}), 2.5 \mathrm{~W} /(\mathrm{m} \cdot \mathrm{K})$, temperature 
difference $\Delta T=\left(T_{w}-T_{r}\right)=6 \mathrm{~K}$. The rest of the physical parameters are accepted: $L=1 \cdot 10^{6} \mathrm{~J} / \mathrm{kg}, \rho_{g}=1.2 \mathrm{~kg} / \mathrm{m}^{3}, \quad \rho_{h}=900 \mathrm{~kg} / \mathrm{m}^{3}, \quad \rho_{w}=980 \mathrm{~kg} / \mathrm{m}^{3}, \lambda_{g}=0.6 \mathrm{~W} /(\mathrm{m} \cdot \mathrm{K})$, $\lambda_{h}=2.11 \quad \mathrm{~W} /(\mathrm{m} \cdot \mathrm{K}), \quad \lambda_{w}=0.58 \quad \mathrm{~W} /(\mathrm{m} \cdot \mathrm{K}), \quad c_{g}=1560 \quad \mathrm{~J} /(\mathrm{kg} \cdot \mathrm{K}), \quad c_{h}=2500 \quad \mathrm{~J} /(\mathrm{kg} \cdot \mathrm{K})$, $\mathrm{c}_{w}=4200 \mathrm{~J} /(\mathrm{kg} \cdot \mathrm{K})$. Table 1 presents the results of the parameter $K$ calculation from the equation (10) and that obtained by the authors of the work [27] as a result of the correlation analysis of experimental data.

Table 1. Comparative analysis of the calculated and experimental data of the parameter $K$.

\begin{tabular}{|c|c|c|}
\hline \multirow{2}{*}{$\begin{array}{c}\text { Thermal conduction of a porous } \\
\text { medium, } \mathrm{W} /(\mathrm{m} \cdot \mathrm{K})\end{array}$} & \multicolumn{2}{|c|}{ Value of the parameter $K, \mathrm{~m} / \mathrm{s}^{1 / 2}$} \\
\cline { 2 - 3 } & $\begin{array}{c}\text { According to the } \\
\text { equation }(10)\end{array}$ & $\begin{array}{c}\text { According to the } \\
\text { data [25] }\end{array}$ \\
\hline 0.5 & $4.44 \cdot 10^{-4}$ & $4.49 \cdot 10^{-4}$ \\
\hline 1.5 & $5.58 \cdot 10^{-4}$ & $5.48 \cdot 10^{-4}$ \\
\hline 2.5 & $7.11 \cdot 10^{-4}$ & $6.97 \cdot 10^{-4}$ \\
\hline
\end{tabular}

As it can be seen from the data in the table, the calculated and known experimental data agree well with each other. Thus, the proposed method can be used to predict the dynamics of the dissociated gas hydrate zone when mining the natural deposits.

Figure 2 presents the results of calculating the temperature fields in the bed calculated by (8)-(9). The following values are accepted as initial data: $L=1 \cdot 10^{6} \mathrm{~J} / \mathrm{kg}, S_{h}=0.2$, $\rho_{g}=1.2 \mathrm{~kg} / \mathrm{m}^{3}, \rho_{h}=900 \mathrm{~kg} / \mathrm{m}^{3}, \rho_{w}=980 \mathrm{~kg} / \mathrm{m}^{3}, \rho_{s}=2000 \mathrm{~kg} / \mathrm{m}^{3}, \lambda_{g}=0.6 \mathrm{~W} /(\mathrm{m} \cdot \mathrm{K})$, $\lambda_{h}=2.11 \quad \mathrm{~W} /(\mathrm{m} \cdot \mathrm{K}), \quad \lambda_{w}=0.58 \quad \mathrm{~W} /(\mathrm{m} \cdot \mathrm{K}), \quad \lambda_{s}=1.2 \quad \mathrm{~W} /(\mathrm{m} \cdot \mathrm{K}), \quad c_{g}=1560 \quad \mathrm{~J} /(\mathrm{kg} \cdot \mathrm{K})$, $c_{h}=2500 \mathrm{~J} /(\mathrm{kg} \cdot \mathrm{K}), \quad c_{w}=4200 \mathrm{~J} /(\mathrm{kg} \cdot \mathrm{K}), \quad c_{s}=1000 \mathrm{~J} /(\mathrm{kg} \cdot \mathrm{K}), T_{f}=286 \mathrm{~K}, T_{w}=390 \mathrm{~K}$, $T_{r}=282 \mathrm{~K}$. In natural deposits, the porosity of hydrate-containing beds can vary over a wide range. For example, the porosity of coal varies within the range of 0.01-0.2 [15]. Fig. 3 shows the results for $m=0.2$, the value of constant $K$ for the accepted initial data is determined $K=0.00038$.

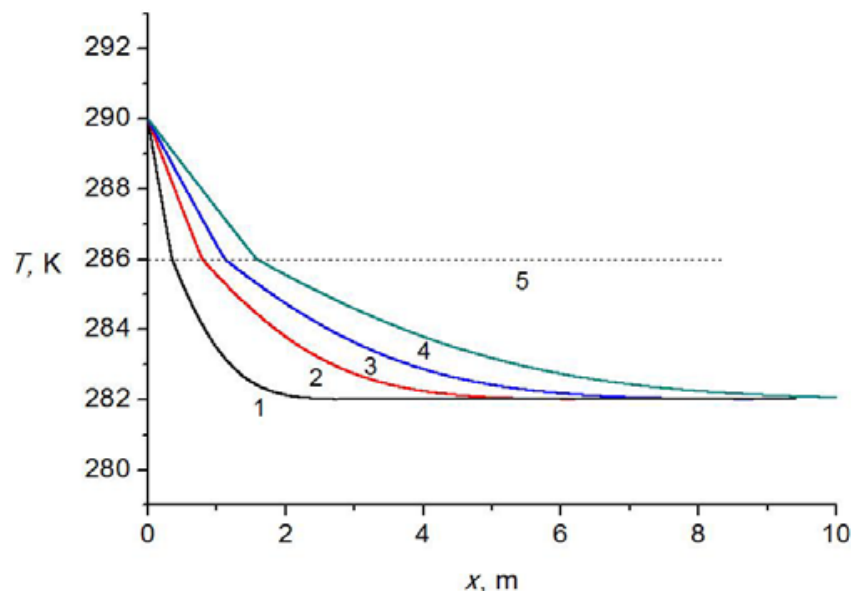

Fig. 2. Temperature in rock mass: $1-\tau=10$ days; $2-\tau=50$ days; $3-\tau=100$ days; $4-\tau=200$ days; 5 - phase temperature.

The graph represented in Fig. 2 makes it possible to assess the temperature pattern in the porous layer during the methane gas hydrate dissociation for 200 days.

Fig. 3 shows a graph of the change in the position of the gas hydrate dissociation line with time in accordance with the equation (7) for layers with different porosity. 


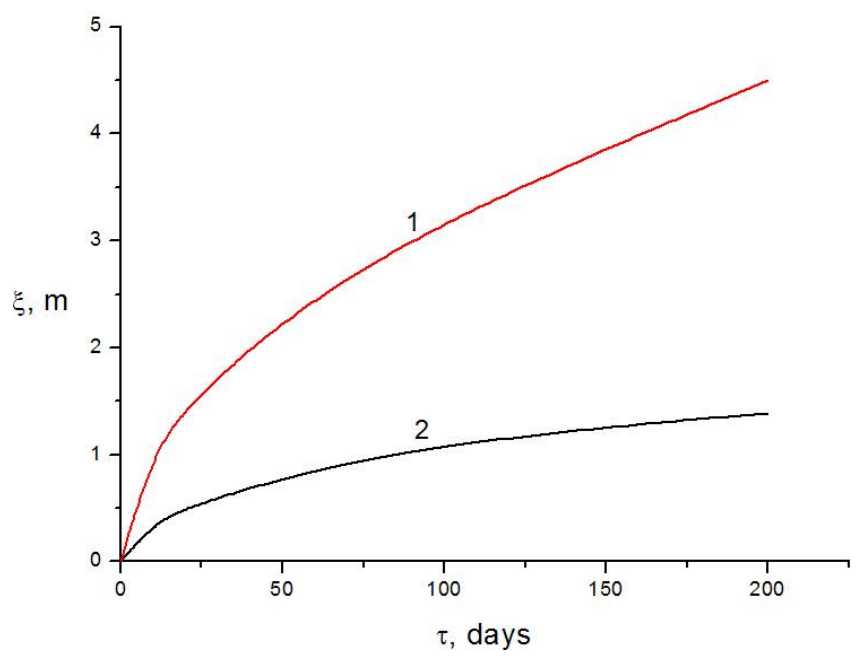

Fig. 3. Interface line position depending on time: $1-m=0.01 ; m=0.2$.

As it can be seen from the data in Fig. 3, porosity influences significantly on the dissociation front movement rate. With an increase in porosity, the front movement rate is slowed down. This is conditioned by an increase in the amount of gas hydrate and the need for large time expenditures for its phase transformation. Fig. 4 shows the porosity influence on the coefficient $K$ value, which determines the dissociation front movement rate.

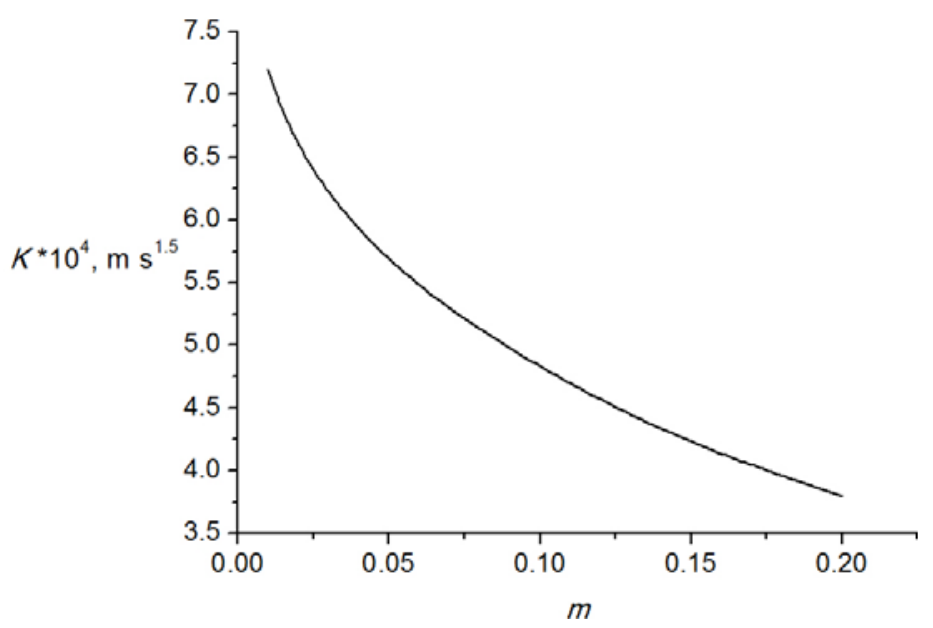

Fig. 4. Dependence of the coefficient $K$ on porosity $m$.

As it can be seen from the data in Fig. 4, with an increase in porosity, the coefficient $K$ decreases. Based on the equation (10) form, the coefficient $K$ value is influenced by the temperature differences $\left(T_{w}-T_{f}\right)$ and $\left(T_{f}-T_{r}\right)$. Fig. 5 presents the research results of the excess temperature $\Delta T=\left(T_{w}-T_{f}\right)$ influence on the coefficient $K$.

It follows from the graph in Fig. 5 that an increase in temperature on the wall of the well leads to an increase in the coefficient $K$ value and, accordingly, to an increase in the dissociation front movement rate. This effect is explained by an increase in thermal flux and, accordingly, thermal energy for the gas hydrate dissociation. 


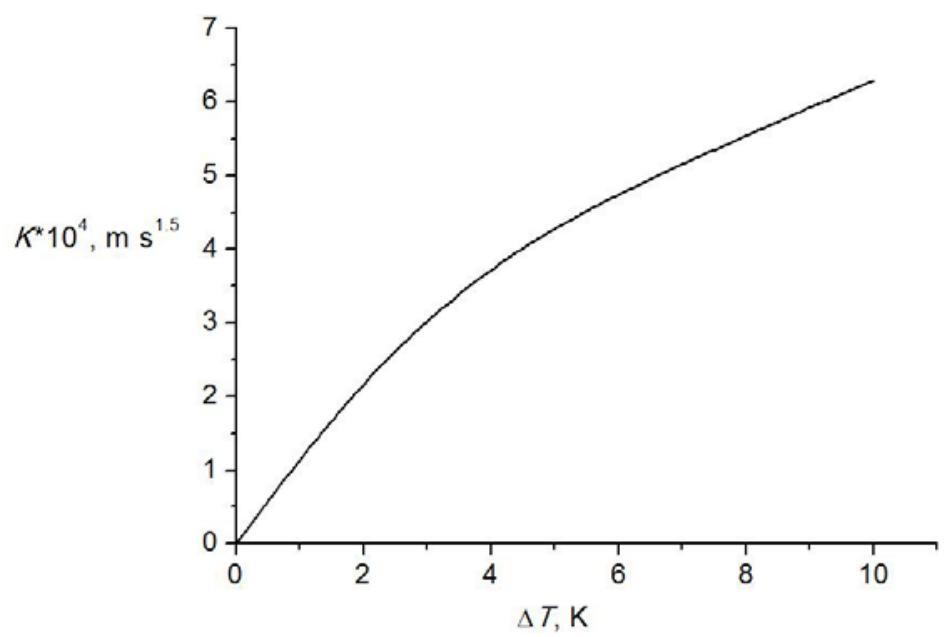

Fig. 5. Dependence of the coefficient $K$ on excess temperature $\Delta T$.

\section{Conclusions}

As a result of the performed research, it is proposed to determine the position of the gas hydrate dissociation front in a porous layer of mine rock in proportion to the square root of time $\xi \sim \sqrt{\tau}$. The use of the Stefan problem solution for a porous layer in determining the proportionality coefficient is substantiated. The dynamics of temperature fields and the dissociation front of methane gas hydrate in a porous layer of mine rock under thermal action on the wall of the well is determined. As a result of computational experiments, it is revealed that the dissociation front movement rate is significantly influenced by the rock layer porosity and the excess temperature. Low porosity of mine rock and an increase in temperature on the wall of the well will intensify the process of gas hydrate dissociation. The proposed method can be used to assess the dynamics of the dissociated gas hydrate zone when mining the natural deposits.

This work was conducted within the framework of the project "Determination of patterns of gas hydrates phase transformations and the stress-strain state of the rock massif and development of innovative geotechnologies" funded by Ministry of Science and Education of Ukraine, No. 0119 U000249.

\section{References}

1. Makogon, Y.F., Holditch, S.A., \& Makogon, T.Y. (2007). Natural gas-hydrates - a potential energy source for the 21st century. Journal of Petroleum Science and Engineering, 56(1-3), 14-31. https://doi.org/10.1016/j.petrol.2005.10.009

2. Bondarenko, V., Kovalevs'ka, I., \& Ganushevych, K. (2014). Progressive technologies of coal, coalbed methane, and ores mining. London, United Kingdom: CRC Press, Taylor \& Francis Group. https://doi.org/10.1201/b17547

3. Pivnyak, G., Bondarenko, V., \& Kovalevska, I. (2015). New developments in mining engineering 2015. London, United Kingdom: CRC Press, Taylor \& Francis Group. https://doi.org/10.1201/b19901

4. Minshull, T.A., Marín-Moreno, H., Betlem, P., \& Bialas, J. (2020). Hydrate occurrence in Europe: A review of available evidence. Marine and Petroleum Geology, (111), 735-764. https://doi.org/10.1016/j.marpetgeo.2019.08.014 
5. Bondarenko, V., Sai, K., Prokopenko, K., \& Zhuravlov, D. (2018). Thermodynamic and geomechanical processes research in the development of gas hydrate deposits in the conditions of the Black sea. Mining of Mineral Deposits, 12(2), 104-115. https://doi.org/10.15407/mining12.02.104

6. Sai, K., Malanchuk, Z., Petlovanyi, M., Saik, P., \& Lozynskyi, V. (2019). Research of thermodynamic conditions for gas hydrates formation from methane in the coal mines. Solid State Phenomena, (291), 155-172. https://doi.org/10.4028/www.scientific.net/SSP.291.155

7. Bondarenko, V., Svietkina, O., Lysenko, R., \& Liu, B. (2020). Methane gas hydrates influence on sudden coal and gas outbursts during underground mining of coal deposits. E3S Web of Conferences, (201), 01002. https://doi.org/10.1051/e3sconf/202020101002

8. Kozhevnykov, A., Khomenko, V., Liu, B., Kamyshatskyi, O., \& Pashchenko, O. (2020). The history of gas hydrates studies: From laboratory curiosity to a new fuel alternative. Key Engineering Materials, (844), 49-64. https://doi.org/10.4028/www.scientific.net/KEM.844.49

9. Bondarenko, V., Sai, K., Ganushevych, K., \& Ovchynnikov, M. (2015). The results of gas hydrates process research in porous media. New Developments in Mining Engineering 2015: Theoretical and Practical Solutions of Mineral Resources Mining, 123-127. https://doi.org/10.1201/b19901-23

10. Fakher, S., Elgahawy, Y., \& Abdelaal, H. (2019). A comprehensive review on gas hydrate reservoirs: Formation and dissociation thermodynamics and rock and fluid properties. International Petroleum Technology Conference. https://doi.org/10.2523/iptc-19373-ms

11. Bondarenko, V., Kovalevska, I., Astafiev, D., \& Malova, O. (2018). Examination of phase transition of mine methane to gas hydrates and their sudden failure - Percy Bridgman's effect. Solid State Phenomena, (277), 137-146. https://doi.org/10.4028/www.scientific.net/SSP.277.137

12. Ovchynnikov, M., Ganushevych, K., \& Sai, K. (2013). Methodology of gas hydrates formation from gaseous mixtures of various compositions. Annual Scientific-Technical Colletion - Mining of Mineral Deposits, 203-205. https://doi.org/10.1201/b16354-37

13. Tsypkin, G.G. (2005). Effect of decomposition of a gas hydrate on the gas recovery from a reservoir containing hydrate and gas in the free state. Fluid Dynamics, 40(1), 117-125. https://doi.org/10.1007/s10697-005-0050-3

14. Yin, Z., Moridis, G., Tan, H. K., \& Linga, P. (2018). Numerical analysis of experimental studies of methane hydrate formation in a sandy porous medium. Applied Energy, (220), 681-704. https://doi.org/10.1016/j.apenergy.2018.03.075

15. Dreus, A.Yu., Bondarenko, V.I., Biletskyi, V.S., \& Lysenko, R.S. (2020). Mathematical simulation of heat and mass exchange processes during dissociation of gas hydrates in a porous medium. Naukovyi Visnyk Natsionalnoho Hirnychoho Universytetu, 5(179). https://doi.org/10.33271/nvngu/2020-5/033

16. Musakaev, N.G., \& Khasanov, M.K. (2019). On the issue of the solutions existence of the problem of gas hydrate dissociation in a porous medium with the formation of an extended region of phase transitions. Journal of Physics: Conference Series, (1404), 012034. https://doi.org/10.1088/1742-6596/1404/1/012034

17. Kozhevnikov, A.A., Sudakov, A.K., Dreus, A.Yu., \& Lysenko, Ye.Ye. (2014). Study of heat transfer in cryogenic gravel filter during its transportation along a drillhole. Naukovyi Visnyk Natsionalnoho Hirnychoho Universytetu, (6), 49-54.

18. Klymenko, V., Gutsul, V., Bondarenko, V., Martynenko, V., \& Stets, P. (2019). Modeling of the Kinetics of the Gas Hydrates Formation on the Basis of a Stochastic Approach. Solid State Phenomena, (291), 98-109. https://doi.org/10.4028/www.scientific.net/ssp.291.98

19. Khabibullin, T., Falcone, G., \& Teodoriu, C. (2011). Drilling through gas-hydrate sediments: Managing wellbore-stability risks. SPE drilling \& completion, 26(02), 287-294. https://doi.org/10.2118/131332-pa

20. Bulat, A., Blyuss, B., Dreus, A., Liu, B., \& Dziuba, S. (2019). Modelling of deep wells thermal modes. Mining of Mineral Deposits, 13(1), 58-65. https://doi.org/10.33271/mining13.01.058

21. Poveshchenko, Yu.A., Podryga, V.O., Popov, I.V., Popov, S.B., Rahimly, P.I., \& Kazakevich, G.I. (2019). Numerical simulation in problems with dissociation of gas hydrates in a 
porous medium in one-dimensional formulation. Uchenye Zapiski Kazanskogo Universiteta. Seriya Fiziko-Matematicheskie Nauki, 161(2), 205-229. https://doi.org/10.26907/25417746.2019.2.205-229

22. Sudakov, A.K., Dreus, A.Yu., Khomenko, O.Ye., \& Sudakova, D.A. (2017). Analytical study of heat transfer in absorptive horizons of borehole at forming cryogenic protecting of the plugging material. Naukovyy Visnyk Natsional'noho Hirnychoho Unyversytetu, (3), 38-42.

23. Vasil'ev, V.I., Popov, V.V., \& Tsypkin, G.G. (2006). Numerical investigation of the decomposition of gas hydrates coexisting with gas in natural reservoirs. Fluid Dynamics, 41(4), 599-605. https://doi.org/10.1007/s10697-006-0078-z

24. Selim, M.S., \& Sloan, E.D. (1989). Heat and mass transfer during the dissociation of hydrates in porous media. AIChE Journal, 35(6), 1049-1052. https://doi.org/10.1002/aic.690350620

25. Sudakov, A., Dreus, A., Ratov, B., \& Delikesheva, D. (2018). Theoretical bases of isolation technology for swallowing horizons using thermoplastic materials. News of the National Academy of Sciences of the Republic of Kazakhstan, Series of Geology and Technical Sciences, 2(428), 72-80.

26. Eckert, E.R.G., \& Drake, Jr.R.M. (1972). Analysis of heat and mass transfer. Tokyo, Japan: McGraw-Hill.

27. Yin, Z., Moridis, G., Chong, Z.R., Tan, H.K., \& Linga, P. (2017). Numerical analysis of experiments on thermally induced dissociation of methane hydrates in porous media. Industrial \& Engineering Chemistry Research, 57(17), 5776-5791. https://doi.org/10.1021/acs.iecr.7b03256 